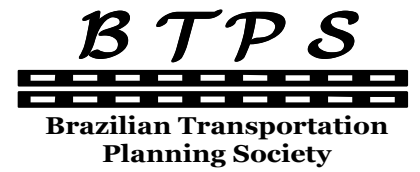

Planning Society

\author{
Journal of Transport Literature \\ Vol. 8, n. 1, pp. 235-264, Jan. 2014 \\ Research Directory
}

\section{JTL|RELIT}

www.transport-literature.org ISSN 2238-1031

\title{
Jogos tecnológicos e a inserção da Embraer perante a nova família de aeronaves para aviação comercial
}

[Technological games and the insertion of Embraer face a new family of aircraft for commercial aviation]

\author{
Bruno da Silva Gomes*, Murilo Batista dos Santos, Pedro Henrique de Alcantara e Silva \\ Universidade Estadual de Campinas - UNICAMP - Brasil
}

Submitted 15 Mar 2012; received in revised form 28 Jan 2013; accepted 29 Jan 2013

\begin{abstract}
Resumo
O objetivo do presente trabalho é apresentar o dilema sucedido no setor de fabricantes de aeronaves para a aviação comercial referente à inserção de novas tecnologias e o ingresso de novas empresas neste mercado ao longo do ano de 2011 . Destacamos a questão da posição ocupada pela empresa Embraer neste cenário diante do duplo desafio que se apresentou: como manter sua posição de destaque no segmento em que já era líder (de 61 a 120 assentos), mediante a chegada de novos concorrentes; e, por outro lado, ponderar a possibilidade de ingressar em um novo segmento que historicamente é dominado pelo duopólio AirbusBoeing (superior a 120 assentos). 0 arcabouço teórico busca articular tais questões à Teoria dos Jogos, instrumental utilizado para analisar as estratégias das empresas concorrentes no setor e suas tomadas de decisões diretamente relacionadas e influenciadas pelas tomadas de decisões dos adversários. As decisões posteriormente efetivadas levaram a Embraer a promover mudanças nos motores das aeronaves da família E-Jet, visando a manutenção da liderança no segmento, ao passo que a possibilidade de ingresso em um novo segmento foi descartada.
\end{abstract}

Palavras-Chave: jogos tecnológicos, Embraer, estratégia, inovação, aviação comercial.

\begin{abstract}
The objective of this paper is to present in summary form the dilemma that was placed in commercial aviation sector, about the insertion of new technologies and the entrance of new firms passed along the year of 2011.The emphasis is the position held by Embraer in this new scene, face to a double challenge that now appears: how to keep its prominent position in the segment that it leads (from 61 to 120 seats), upon the arrival of new competitors; and how to consider the possibility of stepping in a new segment which is historically led by the duopoly Airbus-Boeing (superior to 120 seats). The theoretical framework seeks to articulate these questions to Game Theory, instrument used by microeconomics to analyze the strategies of competitors companies in the sector and their decision making directly related and influenced by the opponent decision making. The decisions taken subsequently led Embraer to promote changes in aircraft engines of the E-Jet family, aiming to maintain the leadership in the segment, while the possibility of entering into a new segment was discarded.
\end{abstract}

Key words: technological games, Embraer, strategy, innovation, commercial aviation.

* Email: brunofinos@hotmail.com.

\section{Recommended Citation}

Gomes, B. S., Santos, M. B. and Alcantara e Silva, P. H. (2014) Jogos tecnológicos e a inserção da Embraer perante a nova família de aeronaves para aviação comercial. Journal of Transport Literature, vol. 8, n. 1, pp. 235-264.

- JTL/RELIT is a fully electronic, peer-reviewed, open access, international journal focused on emerging transport markets and published by BPTS - Brazilian Transport Planning Society. Website www.transport-literature.org. ISSN 2238-1031.

This paper is downloadable at www.transport-literature.org/open-access. 


\section{Introdução}

O objetivo do presente trabalho é apresentar o dilema ocorrido no setor de fabricantes de aeronaves para a aviação comercial mundial referente à inserção de novas tecnologias e o ingresso de novas empresas transcorrido ao longo do ano de 2011. Destacamos a questão da posição ocupada pela empresa Embraer neste cenário diante do duplo desafio que se apresentou: como manter sua posição de destaque no segmento em que já era líder (de 61 a 120 assentos), mediante a chegada de novos concorrentes; e, por outro lado, ponderar a possibilidade de ingressar em um novo segmento que historicamente é dominado pelo duopólio Airbus-Boeing (superior a 120 assentos). O arcabouço teórico busca articular tais questões à Teoria dos Jogos, instrumental este que é utilizado para analisar as estratégias das empresas concorrentes no setor e suas tomadas de decisões diretamente relacionadas e influenciadas pelas tomadas de decisões dos adversários. As decisões posteriormente efetivadas levaram a Embraer a promover mudanças nos motores das aeronaves da família EJet, visando a manutenção da liderança no segmento, ao passo que a possibilidade de ingresso em um novo segmento foi descartada. Tal desfecho fora destacado como um dos cenários factíveis perante os diversos cenários apresentados, o que pode indicar a viabilidade da utilização da Teoria dos Jogos como recurso para estabelecimento de estratégias por parte dos players do complexo mercado de fabricação de aeronaves.

A conjuntura em que se desenvolve o problema central deste trabalho é de alto grau de incerteza permeada pela crise econômica que assola o mundo desde meados de 2008 . No entanto, esta não parece ser vista pelos global players do setor como fator que venha a reduzir bruscamente a sua atividade, embora tenha trazido impactos negativos nas vendas e nas entregas de aeronaves. Por um lado, grande parte dos investimentos e das vendas dos modelos de aeronaves que começam ou começarão a voar foram efetuadas no pré-crise e, por outro lado, a constante necessidade de inovação dos meios de mobilidade - com fins de reduzir custos e diminuir os impactos ambientais - impulsiona investimentos visando às próximas décadas. Ainda há de se considerar o potencial da Ásia - principalmente China - que conta com grande mercado consumidor interno, mas uma produção ainda irrelevante. Tais fatores tornam o setor aeronáutico atrativo tanto para expansão daqueles que já se encontram no mercado como para o nascimento de novos competidores. 
No entanto, diante de tantos atrativos, o setor também se demonstra extremamente complexo, considerando-se a alta intensidade de capital e tecnologia demandadas para que se possa competir de maneira satisfatória. Não é por acaso que a estrutura do mercado aeronáutico é extremamente concentrada, com número relativamente pequeno de empresas que não competem diretamente entre si pois, suas atividades estão separadas por dois grandes segmentos, de acordo com o número de assentos das aeronaves - até 120 assentos e de 120 assentos para cima. Logo, a concorrência de fato se dá entre duas ou três empresas por segmento.

Com apoio dos respectivos Estados, e efetuando parcerias entre si e com as fabricantes de componentes, as ingressantes do setor desejam impor nas próximas duas décadas uma concorrência inédita àqueles que até então dominavam o mercado. É observando este cenário, e as "jogadas" dos adversários, que os executivos da Embraer devem traçar um plano estratégico com fins de aproveitar as vantagens que a empresa já tem por ser referência mundial na fabricação de aeronaves comerciais e expandir, ou no mínimo manter, sua fatia de mercado.

Há ampla discussão em relação à estrutura de produção e investimentos no setor de fabricação aeronáutica, principalmente no que diz respeito aos processos de criação e inovação que envolvem alta tecnologia e engenharia como apresentado em Ferreira (2009), onde são destacadas as profundas transformações na dinâmica de inovação e o aprofundamento da concentração da estrutura produtiva no setor, ressaltando a abertura de possibilidade para fragilização da posição de mercado da empresa brasileira Embraer. No entanto, ainda parece haver brechas para importantes contribuições no que diz respeito à elaboração de modelos para tomada de decisão mediante a complexidade do cenário e dinamicidade do mercado. Sobrinho et al (2005) e Sobrinho et al (2006) propõem um método de Análise por Opções Reais como forma de análise financeira dos investimentos em P\&D na indústria aeronáutica, indicando a possibilidade de utilização de Teoria dos Jogos e árvores de eventos sequenciais para aplicação do método. Seguindo tal caminho, decidimos propor a utilização dos jogos como forma de simulação de cenários de mercado, possibilidade de tomadas de decisão e os respectivos resultados esperados associados a cada escolha como uma forma de guiar os processos de decisão de investimento e inovação no setor de fabricação de aeronaves. 
A aplicação do modelo proposto neste artigo explorará a questão da escolha tecnológica por meio da análise das alternativas que a Embraer e os demais fabricantes tinham à disposição no segundo semestre de 2011. O artigo está estruturado da seguinte maneira: 1) breve descrição do setor de fabricação de aeronaves e apresentação dos marcos teóricos da Teoria dos Jogos, ressaltando um aspecto estrutural desta indústria, qual seja a importância e a magnitude dos investimentos em tecnologia e a necessidade de se envolverem parceiros de riscos nesta empreitada, na qual o balanço entre a opção por inovações radicais e inovações incrementais é tênue; 2) discussão sobre o processo de pesquisa e desenvolvimento (P\&D) e sua essencialidade para o aviação; 3) localização da Embraer no mercado e sua situação corrente em 2010-11, dando ênfase à situação de contestação que ela passou a enfrentar, crescentemente, a partir de meados da década de 2010;4) modelagem de soluções teóricas (hipotéticas) para a Embraer e os demais jogadores que a acompanham, ressaltando em quais circunstâncias (valores hipotéticos de payoffs) cada ação seria racionalmente tomada e; 5) por fim, a partir da narração dos fatos que realmente tomaram forma a partir do segundo semestre de 2011, identificamos qual árvore de jogo se mostra mais aderente à história sendo contada.

\section{A tomada de decisão estratégica no setor de fabricação de aeronaves}

A intensa divisão social do trabalho deixou sua marca no setor de fabricação de aeronaves, segmentando profundamente os processos de fabricação em empresas especializadas em componentes e empresas que efetuam de fato a montagem da aeronave. Segundo dados do COMTRADE, em 2007 51,4\% das transações envolvendo o setor se concentraram no mercado de montagens, enquanto os restantes $48,6 \%$ das transações envolveram o mercado de componentes. Geograficamente as montadoras estão concentradas em EUA e Europa que historicamente gozaram das vantagens de serem a vanguarda econômica e tecnológica do mundo, não obstante, o crescimento de países emergentes como o bloco dos BRICS, tendem a alterar estes dados nas próximas décadas. O Brasil já se destaca neste mercado, sendo o quinto maior exportador de aeronaves de médio e grande porte, posto atingido essencialmente por conta da produção de jatos regionais da Embraer, segmento no qual a empresa brasileira é uma das líderes.

O mercado de componentes aeronáuticos também é de diversa importância e igual complexidade. Além da expressiva participação nas vendas, o valor agregado que representam 
mediante a aeronave concluída é extremamente expressivo. Alguns dos grandes fornecedores, principalmente os de motores, apresentarem faturamento superior ao da maioria das empresas montadoras de aeronaves, fato que pode ser entendido quando se leva em conta que os sistemas de propulsão representam cerca de $20 \%$ do preço de uma aeronave. (OLIVEIRA, 2005, p. 50). Estas empresas também encontram-se concentradas em EUA e Europa, e em menor expressão no Japão.

Fatores como os volumes financeiros que envolve, a natureza de oligopólio concentrado e a crucialidade das decisões que nela se envolvem, convida à utilização de um arcabouço analítico baseado na Teoria dos Jogos. Neste sentido, concentramos nossos esforços na elaboração de alguns modelos, ou seja, representações simplificadas do objeto de estudo, de forma a destacar propositalmente alguns elementos considerados de maior relevância para a compreensão do objeto de estudo, ao passo que se colocam de lado outros fatores que não são considerados determinantes diretos do fenômeno que se quer observar.

A Teoria dos Jogos serve a este propósito geral de apanhar uma situação complexa, onde se possa observar uma interdependência mútua nas tomadas de decisões (interação estratégica) e traçar possíveis resultados lógicos para cada um dos agentes de acordo com a soma de suas ações, o que delimita um "jogo". Assim, a ocorrência de interações estratégicas é pressuposto básico para demarcar a existência do jogo e, portanto, a possibilidade de aplicação da chamada Teoria dos Jogos. Outro pressuposto fundamental para análise satisfatória é considerar que todos os agentes são racionais, ou seja, sempre tomarão as ações maximizadoras de ganhos ou minimizadoras de perdas.

A grande vantagem da Teoria dos Jogos é permitir trabalhar com uma quantidade relativamente pequena de dados para traçar possíveis cenários para o jogo dado, levando à compreensão da lógica situacional. Evidentemente, não é possível replicar um mesmo modelo para todas as situações de interação estratégica, uma vez que diferentes indivíduos, ou organizações, apresentaram diferentes situações de interação: há interações que só ocorrem uma vez (uma proposta única para a tomada de preços); outras que se repetem inúmeras vezes ao longo do tempo (decisão do nível de produção ao longo de inúmeros anos); há situações nas quais as decisões dos agentes envolvidos devem ser tomadas simultaneamente (exemplo de um leilão em que há leitura de propostas a partir de envelopes fechados); e há aquelas em que os agentes envolvidos tomam decisão numa ordem bem definida (possibilidade de entrada 
no mercado, dado que já existem competidores estabelecidos); outras em que os agentes decidem já conhecendo as decisões de seus adversários; etc. Um sumário da Teoria dos Jogos, bem como a exposição de alguns exemplos ilustrativos, pode ser encontrado em Fiani (2006).

Considerando que duas empresas estão prestes a tomar uma decisão simultaneamente, as decisões estratégicas possíveis para este jogo geram uma matriz com valores associados a cada resultado possível (payoffs) acarretando recompensas ou benefícios (no exemplo da Tabela 1, os payoffs são o lucro líquido esperado). A estratégia ótima para um jogador será aquela que maximiza seu payoff esperado, sempre condicional à melhor escolha que seus adversários deverão ter realizado. Por exemplo, se considerarmos a tomada de decisão das líderes do setor aeronáutico mundial (Airbus e Boeing) no que diz respeito à adoção de inovações radicais ou incrementais, podemos traçar o seguinte cenário hipotético:

Tabela 1 - Matriz de payoff para jogo de inovação ${ }^{1}$

\begin{tabular}{lll|l|}
\hline \multirow{4}{*}{ Boeing } & \multicolumn{2}{c}{ Airbus } \\
\cline { 3 - 4 } & Radical & \multicolumn{1}{c}{ Radical } & \multicolumn{1}{c}{ Incremental } \\
\cline { 3 - 4 } & Incremental & 15 & $2 ; 15$ \\
\cline { 3 - 4 } & & & \multicolumn{2}{c}{$10 ; 10$} \\
\cline { 3 - 3 } & &
\end{tabular}

Podemos observar que não há razão racional para nenhuma das duas empresas implementar inovação radical no momento, pois, a massa de investimentos necessários, os riscos e o gap temporal para sua implementação deixariam, dada a situação do jogo, a situação favorável para o adversário que concentrasse esforços numa inovação incremental. Logo, diz-se que a inovação incremental é a estratégia dominante para ambos os agentes, pois ela maximiza os ganhos esperados, qualquer que seja a decisão do oponente. Vemos ainda a emergência de um único equilíbrio, ou um ponto ao qual as empresas chegariam racionalmente ao "jogar" este jogo, segundo as circunstâncias apresentadas: a opção por inovação incremental, neste exemplo hipotético, configura um Equilíbrio de Nash.

Entretanto, as decisões também podem ser tomadas de forma sequencial, com uma empresa tomando a decisão antes de suas concorrentes, deixando para as demais as opções restantes.

\footnotetext{
${ }^{1}$ Elaboração própria a partir de dados hipotéticos.
} 
Conhecidos os possíveis cenários, pode existir uma vantagem em ser o primeiro, já que se tem todas as possibilidades à disposição. A contrapartida são os riscos eminentes em ser pioneiro num processo ainda em desenvolvimento, deixando como legado o aprendizado para os concorrentes através de seus erros ou da tomada de decisão precipitada.

Seguindo o exemplo dado acima, podemos considerar uma nova hipótese onde a Embraer, que não atua na fabricação de aeronaves com capacidade superior a 120 passageiros, cogite entrar neste segmento dependendo da tomada de decisão das líderes Boeing e Airbus.

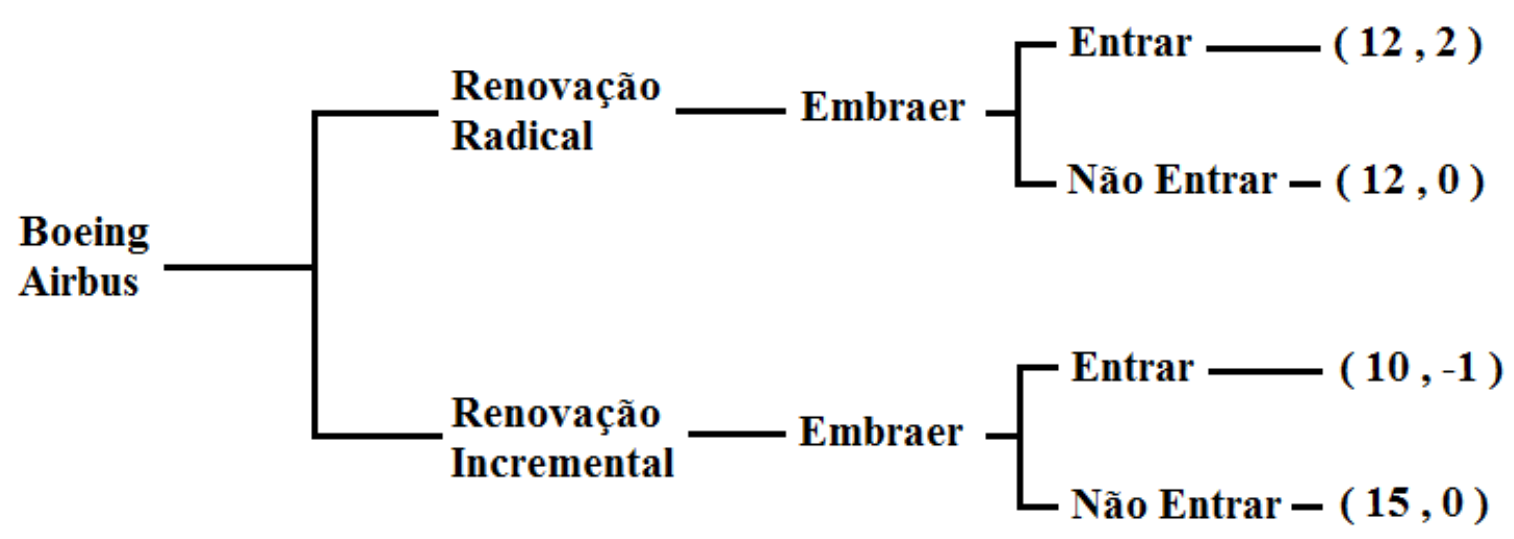

\section{Figura 1 - Exemplo de jogo sequencial ${ }^{2}$}

Vemos que não existe uma estratégia dominante para a Embraer neste caso ilustrativo, pois a atratividade das alternativas depende do ramo da árvore em que se está. Assim, o único cenário positivo para entrada no segmento para a Embraer seria caso as líderes optassem por uma inovação radical (ou seja, confecção de um novo modelo de aeronaves) permitindo à Embraer concorrer em um patamar de menor desigualdade com sua nova aeronave. Vemos ainda a emergência de outro fenômeno: embora o maior ganho esteja no galho 1, ele não é alcançado por conta de a liderança não pertencer à Embraer. As consequências de tal cenário hipotético serão discutidas mais profundamente no decorrer do presente trabalho.

\footnotetext{
${ }^{2}$ Elaboração própria a partir de dados hipotéticos.
} 


\section{A importância da Pesquisa e Desenvolvimento (P\&D)}

Atendo-se especificamente ao setor aeronáutico, o esforço em pesquisa e desenvolvimento tem elevada importância em termos estratégicos, ainda mais quando se leva em conta o papel crucial da inovação. É através dela que se torna possível reduzir custos, poupar tempo, aumentar a segurança e atender a outras demandas das companhias aéreas e da sociedade como todo. Mas, via de regra, o esforço em P\&D representa um ônus considerável para qualquer empresa - no caso da indústria aeronáutica, esse esforço se traduz, por exemplo, na contratação de um verdadeiro exército de engenheiros, cujo papel será fornecer a mão-de-obra e o conhecimento necessários para a realização das pesquisas.

Devido ao papel significativo da P\&D em termos estratégicos, os gigantes da fabricação de aeronaves precisam comprometer parcelas cada vez maiores do seu capital com o investimento na pesquisa de novas tecnologias, que vão desde o desenvolvimento de motores mais eficientes até a obtenção de novos materiais, mais leves e resistentes. Para que se tenha uma ideia do intenso volume de recursos envolvido nos processos de pesquisa, entre os anos de 2007 e 2009 a Boeing, segundo seu relatório anual de 2010, investiu algo em torno de 14,2 bilhões de dólares em pesquisas, dos quais 2,7 bilhões foram mobilizados para a realização de voos de teste para o desenvolvimento do modelo 787. Ainda de acordo com o mesmo relatório, somando-se apenas o ano de 2010, foram destinados 4,1 bilhões de dólares às pesquisas, montante equivalente a algo em torno de $15 \%$ das receitas da empresa. (The Boeing Company, 2010) Os esforços da empresa norte-americana para desenvolver novas tecnologias ilustram a importância da inovação para os fabricantes de aeronaves.

Um segundo aspecto a somar complexidade à tarefa de desenvolver novas aeronaves é o intenso encadeamento envolvido no processo de concepção e fabricação de aeronaves: o processo de fabricação de uma aeronave envolve uma infinidade de componentes, distribuídos em diferentes categorias e confeccionados por diferentes fornecedores - os componentes de um avião incluem desde sofisticados computadores e sistemas de navegação até simples estofados - o que implica na capacidade e necessidade de assimilar avanços ocorridos nos mais diversos setores, às vezes tão díspares quanto a climatologia, a computação e a química. 


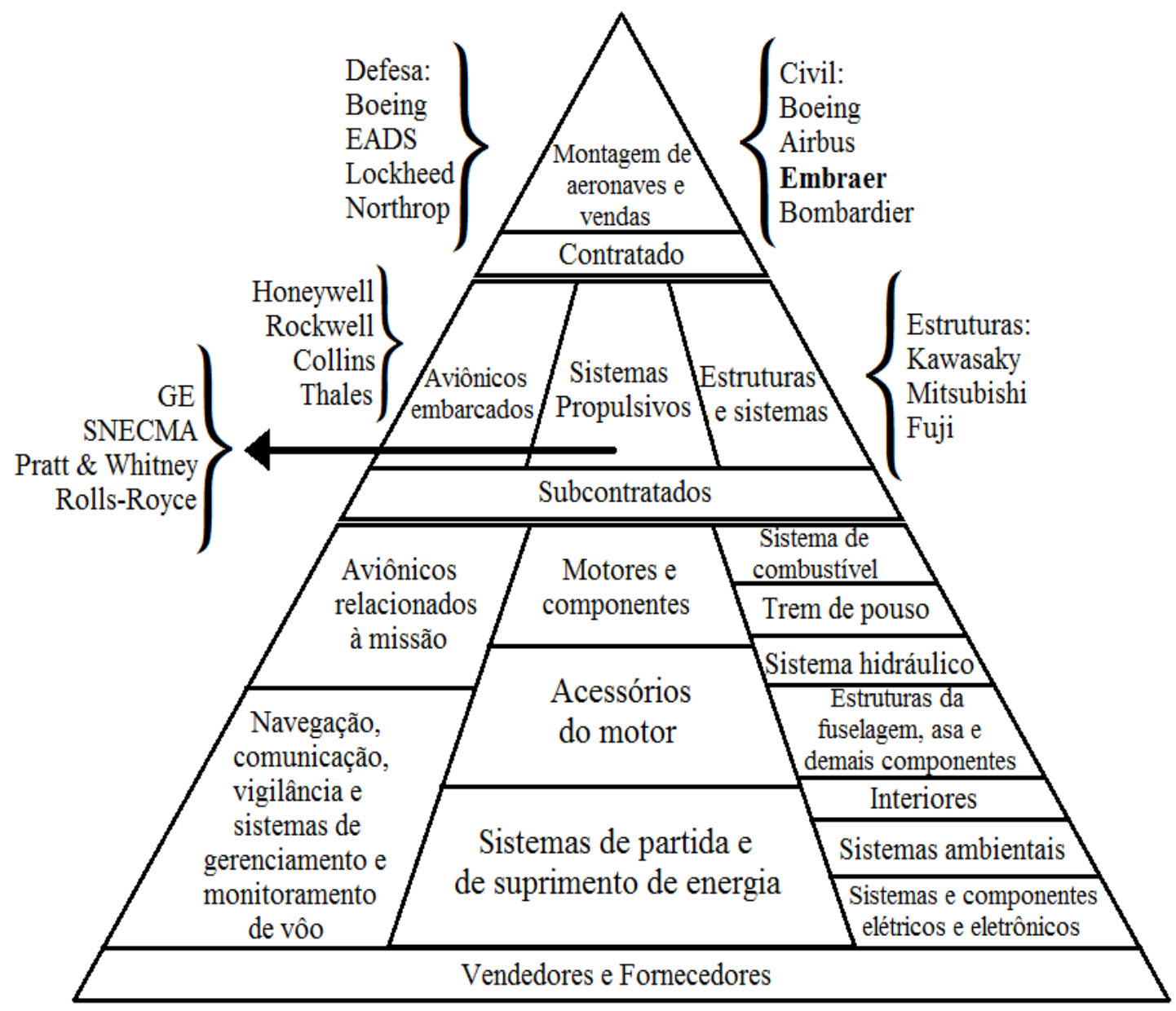

Figura 2 - Indústria aeronáutica e cadeia de fornecedores ${ }^{3}$

Em geral, a indústria aeronáutica passa por ciclos de inovação, conforme tratado, por exemplo, por Bettini (2007) e Brito e Bragança (2008): devido à dinâmica do mercado, há determinados momentos em que o surgimento de novas demandas exige o estabelecimento de novos parâmetros, que irão ditar o desenvolvimento do setor por certo período de tempo. Quando esses parâmetros já não permitem atender às exigências do mercado, recomeça um novo ciclo, para que se chegue a um novo patamar, capaz de ditar as inovações durante essa nova etapa ou estágio tecnológico. Esses momentos de mudança nos patamares envolvem, obviamente, maior grau de risco, tendo em vista que as inovações determinadas nesses pontos críticos serão responsáveis pelo encaminhamento dos avanços tecnológicos das aeronaves por vários anos - todas as atualizações de um determinado ciclo serão influenciadas pela nova diretriz. No caso, o ciclo de inovação pode ser classificado de acordo com o tipo de projeto

\footnotetext{
${ }^{3}$ Ferreira (2009) pág. 72.
} 
desenvolvido: pode-se começar um processo de inovação radical, com a criação de modelos totalmente novos - que pode ainda englobar o desenvolvimento de novas famílias; ou promover-se uma inovação incremental, ou seja, desenvolver melhorias significativas, porém mais simples, a partir de modelos de aeronaves já existentes.

Recuperando a noção segundo a qual a indústria aeronáutica organiza-se por meio de uma intrincada cadeia de fornecedores, os riscos envolvendo os momentos de transição entre ciclos tecnológicos tornam-se ainda maiores: como o processo de fabricação de aeronaves envolve uma vasta gama de diferentes componentes, é necessário que os projetos consigam englobar todos os elos da corrente, mantendo a delicada harmonia entre as diferentes etapas da produção. Por exemplo, o desenho de uma nova fuselagem que possibilite maior aerodinâmica pode exigir que materiais mais resistentes e maleáveis sejam desenvolvidos para que o modelo saia da prancheta. Ao mesmo tempo, poderá ser necessário que os fornecedores de componentes como trem de pouso criem um novo produto que se encaixe perfeitamente na nova fuselagem, o que por sua vez pode exigir a criação de um novo modelo de pneus, ou ainda o desenvolvimento de um novo tipo de suspensão. Uma narrativa acerca das complexidades envolvidas em processos desta natureza podem ser encontradas, por exemplo, em Altfeld (2010).

Assim, nota-se que as decisões acerca dos processos de inovação - desde a escolha do melhor momento para se iniciar a mudança até o grau de intensidade desta - envolvem um imensurável grau de complexidade e, portanto, configuram momentos de elevado risco para as empresas - tendo em vista que qualquer desajuste entre as inúmeras modificações encadeadas pela inovação significará pesados danos financeiros. Pode-se dizer que a indústria aeronáutica está passou ao longo de 2011 por um desses períodos decisivos: o desenvolvimento de projetos como o Airbus A-380 e o Boeing 787 configuram uma evidência clara de que este momento fora de rearranjo dos patamares tecnológicos, e também que este rearranjo pode ser penoso e custoso: as multas compensatórias pelos atrasos nas entregas destes dois aviões alcançaram cifras de centenas de milhões de dólares e puseram pressão sobre a rentabilidade dos programas para os fabricantes.

Uma das questões-chave que tem norteado o processo recente de desenvolvimento de novas aeronaves é a busca pela otimização da eficiência energética. A pressão das companhias aéreas pelo desenvolvimento de novas tecnologias que otimizem o consumo de combustível 
tem sido crescente, algo condizente com a tendência de aumento nos preços dessa commodity ao longo das últimas décadas.

Neste contexto, o desenvolvimento de novos motores configura um ponto fulcral para a dinâmica de inovação, pois além de ser fundamental para a otimização do consumo de combustível, permite aumento da autonomia dos aviões, menores níveis de emissão de resíduos, diminuição de ruídos, maior resistência e durabilidade, redução da necessidade de revisões e aumento da vida útil das aeronaves. Assim, fabricantes de aeronaves como Airbus, Boeing, Bombardier, a própria Embraer e a Mitsubishi, por um lado, em conjunto com fabricantes de turbinas aeronáuticas como a General Electric (GE), Pratt \& Whitney e a inglesa Rolls Royce têm direcionado seus esforços a dois pontos cruciais: o desenvolvimento de sistemas de propulsão mais econômicos e a busca por novos compostos materiais - mais leves e maleáveis que os utilizados no processo de fabricação atualmente e que possibilitem, portanto, maior economia de combustível e maior agilidade na construção das aeronaves.

Esta exposição serviu para esclarecer o caráter imperioso da pesquisa e do desenvolvimento na indústria aeronáutica. Sem o esforço para descoberta de novos métodos e tecnologias, que vão desde a alocação de recursos próprios até a formação de complexas parcerias para a mitigação de riscos, seria impossível acompanhar as exigências do consumidor final, ou seja, as empresas aéreas e, em última instância, os passageiros. Sabe-se, no entanto, que os esforços em pesquisa e desenvolvimento são custosos, arriscados e não se configuram em uma alternativa sempre superior às demais. Nos marcos da Teoria dos Jogos, o esforço inovativo nem sempre se traduz em uma estratégia dominante, tal como pudemos demonstrar com o jogo hipotético ilustrado na Figura 1.

A etapa seguinte de nossa análise dará maior ênfase às questões que ligam a Embraer de maneira mais explícita, direta, a este problema de posicionamento perante ciclos tecnológicos. 


\section{A Embraer e as escolhas em mãos}

A Embraer é, a depender da métrica utilizada ${ }^{4}$, a líder mundial no segmento de jatos regionais, produzindo duas famílias de aviões: a primeira e mais antiga é a família ERJ 145, com capacidade de 35 a 50 assentos, que teve um grande êxito comercial, mas nos últimos anos conforme indica a Figura 3 - viu suas vendas bastante reduzidas em decorrência da saturação da sua faixa de mercado, principalmente nos países desenvolvidos. A segunda e mais recente é a família EMB-170/190, também chamada de E-Jets, que apresenta quatro modelos de aeronave com capacidade entre 70 e 120 assentos e consolidou a posição da Embraer no mercado da aviação comercial.

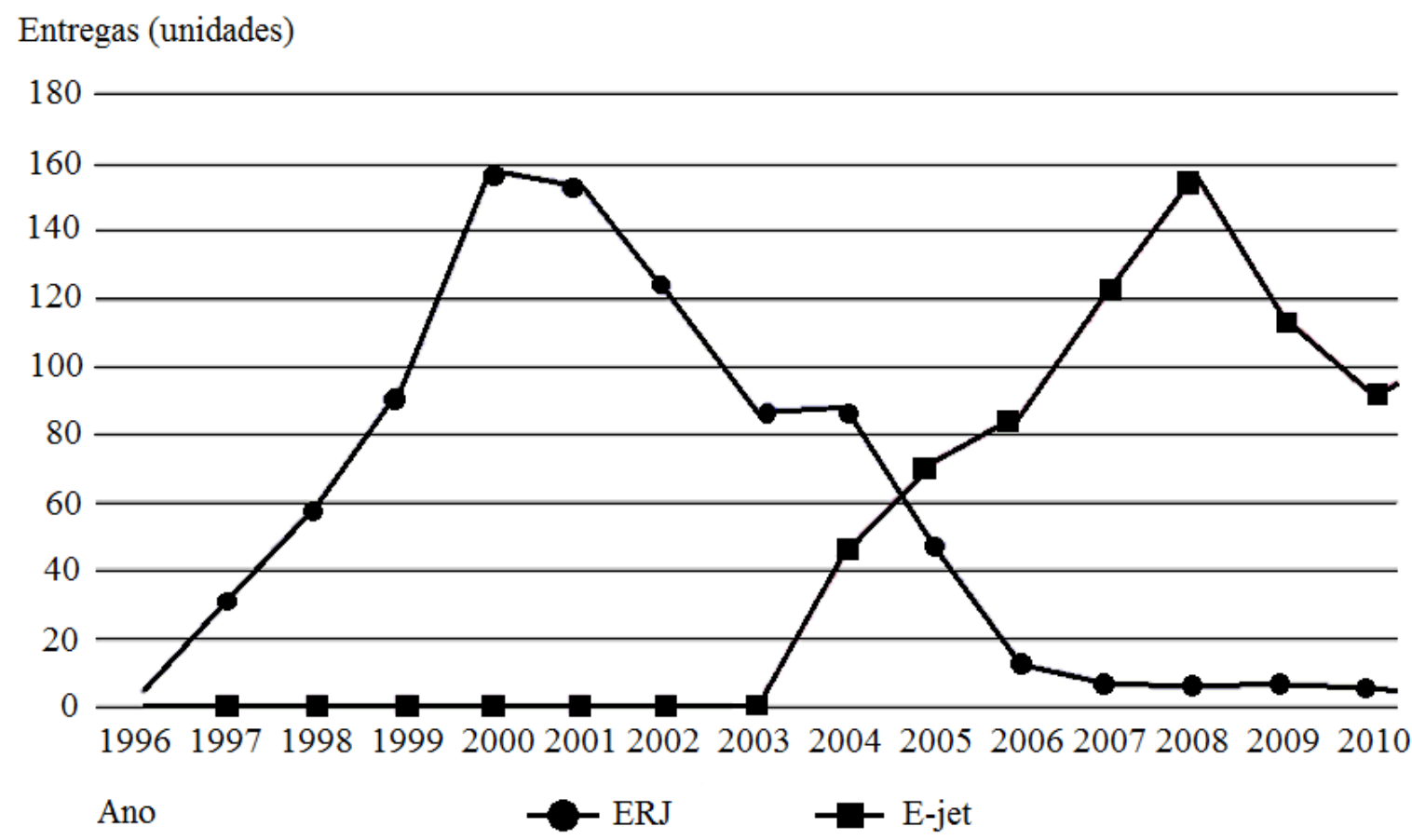

Figura 3 - Embraer: Modelos de Aeronaves Entregues (1996 - 2010) 5

A Figura 3 também ilustra claramente a ideia de ciclos de inovação e de que aeronaves têm um ciclo de vida comercial: a família ERJ atinge seu auge entre os anos 2000 e 2001, e em seguida, as vendas começam a cair de maneira significativa, mostrando que o ciclo da família

4 Total de encomendas, total de entregas, backlog (encomendas a serem entregues), número de operadores, receita total, lucratividade, número de funcionários, etc. Consoante a métrica utilizada, a Bombardier pode ascender à liderança do segmento.

5 Elaboração própria a partir de dados obtidos em Embraer relatório anual (2000-2010). 
de pequenos jatos se encaminhava ao estágio final. No auge deste ciclo, a Embraer agiu de maneira ativa e inovou com o lançamento da família de E-Jets, dando início a um novo ciclo e obtendo grande sucesso comercial. Com o lançamento da família dos E-Jets a Embraer obteve uma grande vantagem sobre a canadense Bombardier - sua principal concorrente no setor de jatos regionais. Apesar de ter ingressado no segmento posteriormente - os E-Jets estão sendo vendidos desde 2004, ao passo que o modelo similar canadense começou a ser comercializado no último ano da década de 1990 - esta aparente fraqueza se traduziu em uma oportunidade concreta para a Embraer, pois o fabricante brasileiro teve uma boa margem de tempo para desenvolver uma linha de aeronaves razoavelmente superior aos modelos da concorrente. Ademais, pelo fato de os E-Jets constituírem uma família completa de modernas aeronaves com desempenho e qualidade que se assemelham aos das grandes aeronaves comerciais, seu apelo junto às empresas aéreas foi significativamente superior ao exercido pelas aeronaves concorrentes da Bombardier: um dos principais argumentos de venda da Embraer em relação a seu produto diz respeito à possibilidade que eles abrem para que empresas aéreas os operem em conjunto com aeronaves de maior porte (aeronaves de corredor único da Airbus ou da Boeing) mantendo-se o nível de serviço aos passageiros.

Porém, a Figura 3 também mostra que o ciclo dos E-Jets pode ter atingido seu ápice em 2008, em um processo possivelmente intensificado pela crise econômica mundial e que, embora haja uma aparente reação, a entrada nos próximos anos de novos modelos desenvolvidos pela concorrência poderá ter efeito sobre as entregas da fabricante brasileira, o que coloca a Embraer diante de um novo desafio pela inovação. Desta forma, a despeito da investida nesse segmento, o de aeronaves comerciais com capacidade entre 70 e 120 assentos, ter possibilitado uma importante vantagem competitiva para a Embraer, vez que as companhias aéreas procuraram adequar a capacidade de suas aeronaves à demanda por determinadas rotas com a finalidade de alcançar uma maior rentabilidade, o fato é que este ímpeto inovativo pode ter alcançado seu ápice e pode ter começado a dar sinais de exaustão.

Dentre os fatores a exercer pressão sobre o desempenho de vendas da família dos E-Jets encontra-se um protagonizado pela própria Bombardier, a rival mais tradicional da Embraer: em Julho de 2008, o fabricante canadense tomou a decisão de manter os modelos CRJ no segmento de até 100 assentos, mas lançou uma nova família (CSeries), com o intuito de, ao 
mesmo tempo, conseguir enfrentar tanto os E-Jets de maior capacidade quanto alguns modelos fabricados por Airbus e Boeing.

\subsection{Os novos concorrentes diretos da Embraer}

Desde que emergiu como fabricante de destaque no segmento de aeronaves a jato para até 120 assentos, a Embraer basicamente enfrentou a forte concorrência de uma única rival à altura, a Bombardier. Embora em alguns momentos os segmentos onde a liderança da empresa brasileira e das duas líderes mundiais - Boeing e Airbus - tenham se misturado, isso não chegou a significar uma ameaça realmente concreta para a Embraer, haja vista as tentativas frustradas da Airbus de emplacar uma versão reduzida de seus aviões da família A320 ou então as dificuldades encontradas pelos modelos menores da família 737 da Boeing: de fato, os modelos A318 e B737-600 são as variantes de menor sucesso comercial nas respectivas famílias destes dois fabricantes, alegadamente devido à relação desconcertante entre a capacidade de transporte de carga paga e o consumo de combustível. Ademais, ressalta-se, a título de curiosidade, que os projetos de modelos ainda menores da Airbus - os A316 e A317, membros do programa $\mathrm{AE} 31 \mathrm{X}$ - nunca deixaram as pranchetas de projeto (Norris e Wagner, 1999).

O que ocorre na atual conjuntura é que novas empresas, principalmente do continente asiático, começam a fabricar ou estão desenvolvendo modelos de aviões no segmento no qual a Embraer concentra suas vendas. Entre elas podemos destacar a japonesa Mitsubishi, que já começou o desenvolvimento da linha MRJ, que segundo a empresa chegará ao mercado no máximo até 2014 e contará com uma gama de modelos com capacidade para transportar entre 70 e 90 passageiros e proporcionar uma economia de até $20 \%$ de combustível frente às outras aeronaves de mesmo porte disponíveis atualmente no mercado. Porém, diferentemente de outras empresas, a Mitsubishi terá como inovação o motor fornecido pela Pratt \& Whitney, que com o recente desenvolvimento de uma nova tecnologia permite diminuir o consumo de combustíveis, os níveis de poluentes e de ruídos. Outra inovação importante é a utilização de fibra de carbono em parte da fuselagem. Assim, os MRJ prometem trazer uma maior autonomia de voo em relação aos E-Jets da Embraer. (Mitsubishi Aircraft Corporation, 2011) 
O chinês ARJ-21 da Comac, projetado para o transporte de 70 a 100 passageiros, já existe enquanto protótipo e encontra-se em fase de testes para homologação. Ainda antes de haver qualquer entrega para clientes comerciais, o avião já acumula 239 encomendas. A Comac conta com o apoio de 19 grandes fabricantes de componentes europeus e estadunidenses, além do conhecimento acumulado junto à McDonnell Douglas ${ }^{6}$. Outra parceira importante é a General Eletric, que produzirá o motor. É interessante destacar que ao firmar parcerias com empresas respeitadas no setor a Comac diz a seus potenciais concorrentes que suas intenções de brigar pelo seu cobiçado mercado interno são bastante sérias, o que lhe confere credibilidade. O governo da China, com esta empreitada na indústria aeronáutica nacional, busca reduzir a dependência do seu mercado das fabricantes Airbus e Boeing para atender a demanda interna por aeronaves comerciais. (Comac, 2011)

A russa Sukhoi desenvolveu uma família de três jatos regionais com capacidade de transporte de 75 a 100 assentos. A iniciativa é apoiada pelo governo russo e contou com ajuda técnica da Boeing: a intenção é substituir modelos antigos, ainda dos tempos de União Soviética. Assim como a fabricante chinesa, a Sukhoi conta com a participação de muitos fornecedores estrangeiros, principalmente europeus, além da participação do Estado russo (Sukhoi Civil Aircraft, 2011).

Em operação desde 2011, os primeiros modelos Superjet 100 começaram a operar no mercado russo e armênio - até meados de 2011 apenas sete aeronaves haviam sido entregues, mas só o fato do projeto da Sukhoi ter entrado em operação na área comercial já serve para tornar mais visíveis os sinais de que mudanças estão por vir: a disputa pelos céus russos e de países sob sua zona de influência - outros países que sediam empresas que encomendaram o modelo são a Itália, o México, a Tailândia e a Indonésia - promete esquentar nos próximos anos. Mais um ponto que credencia a Sukhoi como potencial ameaça é a tradição da Rússia em termos de engenharia: por muitos anos a União Soviética conseguiu disputar em termos de inovação tecnológica com os Estados Unidos e, apesar da desindustrialização que atingiu o leste europeu desde meados da década de 1980, não se pode negar que os russos têm sim potencial para explorar esse mercado onde a inovação é tão crucial. (Sukhoi, 2011)

\footnotetext{
${ }^{6}$ Extinta fabricante de aeronaves estadunidense que foi incorporada pela Boeing em 1997 e atuou por algum tempo por meio de uma joint venture na China.
} 
Além disso, conforme destacado no início desta seção, a família CSeries da Bombardier promete se colocar como concorrente dos E-Jets da Embraer, já que uma das versões da nova família de modelos canadense deve ter 100 assentos - embora o foco da CSeries seja o mercado entre 120 e 150 assentos.

Apesar de não considerar os novos concorrentes como uma grande ameaça no curto prazo ${ }^{7}$, a situação exige da Embraer uma resposta frente à eminente possibilidade de perder espaço no mercado nas próximas décadas. Em que medida a Embraer responderia com novas tecnologias dentro de seu próprio segmento de mercado ou explorando novos segmentos é o desafio que se coloca para a empresa brasileira. Afinal, a tendência é de que a Embraer passe a enfrentar um acirramento da concorrência no mercado de aeronaves com capacidade para 60 a 120 passageiros, levando-se em conta que além da tradicional concorrente Bombardier, a fabricante brasileira terá pela frente a entrada de concorrentes da China, Rússia e Japão. A Tabela 2 ilustra o cenário competitivo com que a Embraer se defronta em seus segmentos de atuação na aviação comercial.

Tabela 2 - Principais Fabricantes de Jatos Comerciais com até 120 assentos: Modelos por categoria $^{8}$

\begin{tabular}{lccc}
\hline Empresas (Grupos) & \multicolumn{3}{c}{ Categorias (número de assentos) } \\
\cline { 2 - 4 } & $31-60$ & $61-90$ & $91-120$ \\
\hline Airbus (EADS) & & A-318 \\
Bombardier Aerospace & CRJ-200 & CRJ-700/900 & CRJ-1000 e C-Series \\
Embraer & ERJ-135/145 & EMB-170/175 & EMB-190/195 \\
AVIC I & & ARJ-21.700 & ARJ-21.900 \\
Sukhoi & SSJ-100.75 & SSJ-100.95 \\
Mitsubishi (MHI) & MRJ-70 & MRJ-90 \\
\hline$\square$ Aeronaves em operação & &
\end{tabular}

${ }^{7}$ Em declaração dada em abril de 2011 o presidente da Embraer, Frederico Curado afirmou que "Não é ameaça hoje, ou nos próximos 5 a 10 anos. Daqui a 20, 25 anos, pode ser uma tremenda [...], dependendo da obstinação deles" (Portal Estadão - acessado em 19/11/2011).

${ }^{8}$ Elaboração própria a partir de dados obtidos em Ferreira (2009) pág.164. 
Apesar da Sukhoi e da AVIC I não possuírem experiência na comercialização de aeronaves no ocidente e de dois modelos, C-Series e MRJ, ainda estarem na fase de estudo e desenvolvimento, a perspectiva é de que a Embraer assista ao acirramento da concorrência em seus domínios. No entanto, a empresa brasileira ainda deverá manter algum fôlego nesse segmento de aeronaves, pois os modelos recém-lançados pela empresa russa e, principalmente, pela empresa chinesa, muito provavelmente estarão voltados para atender majoritariamente seus respectivos mercados internos. Porém, o ponto fundamental é qual montante de inovações tecnológicas estas novas aeronaves irão incorporar, principalmente no campo dos materiais e das turbinas, e em que medida a competitividade dos E-Jets será afetada.

Estes fenômenos de entradas e de inovação em seu principal nicho de mercado colocou a empresa brasileira em um complexo dilema: renovar, talvez precocemente, sua linha de E-Jets - cuja primeira entrega aconteceu em 2004 - ou investir no desenvolvimento de uma nova linha, com capacidade para comportar até 150 assentos? A análise deste problema será aprofundada em um ponto mais adiante deste trabalho.

\subsection{Perspectivas de mercado}

Em paralelo a toda a dinâmica competitiva narrada na seção anterior, fabricantes de aeronaves realizam estudos que subsidiam as ações de suas áreas comerciais e industriais, por meio de inteligência de mercado e planejamento estratégico. Atendo-se especificamente ao fabricante brasileiro, o relatório mais recente da Embraer prevê que a frota em operação ao redor do mundo deverá crescer mais de $80 \%$ no período que vai de 2011 a 2030 - conforme indica a Tabela 3. 


\section{Tabela 3 - Aviação comercial - Evolução da frota mundial (2011-2030) - Aeronaves a jato de 30 a 120 assentos e a turboélice ${ }^{9}$}

\begin{tabular}{lcccc}
\hline Região/Ano & $\mathbf{2 0 1 0}$ & $\mathbf{2 0 3 0}$ & Participação em 2030 & Crescimento \\
\hline África & 315 & 680 & $5,99 \%$ & $115,87 \%$ \\
Ásia & 665 & 1615 & $14,22 \%$ & $142,86 \%$ \\
China & 160 & 1110 & $9,78 \%$ & $593,00 \%$ \\
Europa & 1395 & 2485 & $21,88 \%$ & $78,00 \%$ \\
América Latina & 610 & 1305 & $11,49 \%$ & $113,93 \%$ \\
Oriente Médio & 130 & 385 & $3,39 \%$ & $196,15 \%$ \\
América do Norte & 2590 & 3090 & $27,21 \%$ & $19,31 \%$ \\
Rússia & 440 & 685 & $6,03 \%$ & $55,68 \%$ \\
\hline Mundo & $\mathbf{6 3 0 5}$ & $\mathbf{1 1 3 5 5}$ & $* * *$ & $\mathbf{8 0 , 1 0 \%}$
\end{tabular}

Esta projeção contém uma informação crítica: a China apresentará - caso as previsões se concretizem - um impressionante crescimento de 593\%, fazendo com que o mercado chinês sozinho represente quase $10 \%$ do mercado mundial. Caso o mercado chinês seja predominantemente atendido por fabricantes internos, isto significará que o mercado de maior crescimento do mundo estará fechado para estrangeiros, incluindo-se a brasileira Embraer.

Outra modalidade de projeção de mercado ocorre por meio da segmentação segundo categoria de produtos. Neste sentido, as projeções contidas em Embraer Market Outlook (2011) também indicam que quase $22 \%$ das novas entregas até 2030 serão de modelos cujo número de assentos estará entre 61 e 120, a fatia de mercado em que se encontram os E-Jets da Embraer. No entanto, a análise da Tabela 4 aponta que a maior fatia do mercado continuará a ser representada pelos modelos com mais de 120 assentos, cujas encomendas serão responsáveis por algo em torno de $70 \%$ das entregas realizadas entre 2011 e 2030. Percebe-se

\footnotetext{
${ }^{9}$ Elaboração própria segundo dados da Embraer Market Outlook (2011).
} 
então um indício de que a força desse nicho - hoje dominado pelas líderes Boeing e Airbus ainda deverá se manter por muito tempo no mercado de aviões comerciais.

Tabela 4 - Projeção de Novas Entregas até 2030 (Mundo) $^{10}$

\begin{tabular}{lcccc}
\hline Assentos & 2011-2020 & $\mathbf{2 0 2 1 - 2 0 3 0}$ & $\mathbf{2 0 1 1 - 2 0 3 0}$ & Participação \\
\hline $30-60$ & 1.080 & 1.790 & 2.870 & $9,13 \%$ \\
$61-90$ & 1.265 & 1.405 & 2.670 & $8,49 \%$ \\
$91-120$ & 1.845 & 2.280 & 4.125 & $13,12 \%$ \\
$121-210$ & 7.410 & 8.775 & 16.185 & $51,49 \%$ \\
Mais de 210 & 2.570 & 3.015 & 5.585 & $17,77 \%$ \\
\hline Total & $\mathbf{1 4 . 1 7 0}$ & $\mathbf{1 7 . 2 6 5}$ & $\mathbf{3 1 . 4 3 5}$ & $\mathbf{1 0 0 \%}$
\end{tabular}

\section{Estruturação de cenários}

Como vimos anteriormente, o cenário competitivo que se formou a partir do final da década de 2000 levou a Embraer a cogitar duas alternativas, em teoria mutuamente excludentes por conta dos custos envolvidos: realizar algum grau de renovação em seu produto E-Jet, ou partir para a competição por um segmento de mercado de capacidade de transporte de passageiros e de alcance superiores. Como analisar esta decisão que o fabricante brasileiro teve de tomar?

Tendo como base a teoria dos jogos sequenciais, podemos definir, para a Embraer e para os demais fabricantes incumbentes - Airbus, Boeing e Bombardier - um conjunto de quatro alternativas de cenários possíveis, ou simplesmente "estratégias":

${ }^{10}$ Elaboração própria segundo dados da Embraer Market Outlook (2011). 
i. Nada fazer;

ii. Realizar uma inovação incremental, ou seja, promover atualizações leves no produto. Exemplos de atualizações leves incluem nova aviônica, nova arquitetura de interiores, e ainda a previsão de incluir aletas (winglets) como opção em retrofit;

iii. Realizar uma inovação radical, ou seja, promover atualizações pesadas no produto. Dentre as inovações consideradas pesadas, podem-se incluir concepção de novas asas para uma mesma fuselagem, concepção de nova fuselagem para um mesmo conjunto de asas, remotorização que envolva a necessidade de reforços estruturais nas asas e alteração na estrutura do trem de pouso, e ainda alteração nos materiais usados na fabricação de componentes estruturais críticos (asas e fuselagem), ao se substituir em larga escala, por exemplo, alumínio por materiais compósitos;

iv. Partir para a concepção de uma aeronave em um segmento superior de mercado em termos de capacidade e/ou alcance, tirando proveito do fato de a base corrente de clientes (empresas aéreas) estar sujeita a pressões constantes advindas de economias de densidade, especialmente atuantes em uma condição de preço crescente para o petróleo, insumo essencial para o transporte aéreo. Parcela deste estímulo ao crescimento no tamanho médio das aeronaves pode ser compreendida a partir da interpretação de Bettini e Oliveira (2011) para a evolução da estratégia da empresa brasileira TAM.

Conforme visto na Seção 1, nem sempre existe uma estratégia dominante para um jogador e, em caso de interdependência estratégica, nem sempre o resultado mais favorável (em termos absolutos) prepondera. Com esta ressalva em mente, como analisar as possibilidades que Airbus e Boeing, por um lado, e Embraer, por outro, tinham em mãos ao longo de 2011 ?

De início, abordemos o seguinte caso: a Embraer pondera entrar (Estratégia iv) ou não entrar (qualquer das estratégicas i a iii) em um segmento de mercado superior, enquanto as concorrentes (Airbus e Boeing) têm à disposição três estratégias possíveis (i, ii ou iii). Admitamos, em um primeiro exercício, que as incumbentes Airbus e Boeing exerçam sua liderança e, assim, coloquem a Embraer como seguidora em um jogo sequencial. A Figura 4 ilustra as alternativas que este tipo de interação abre. 


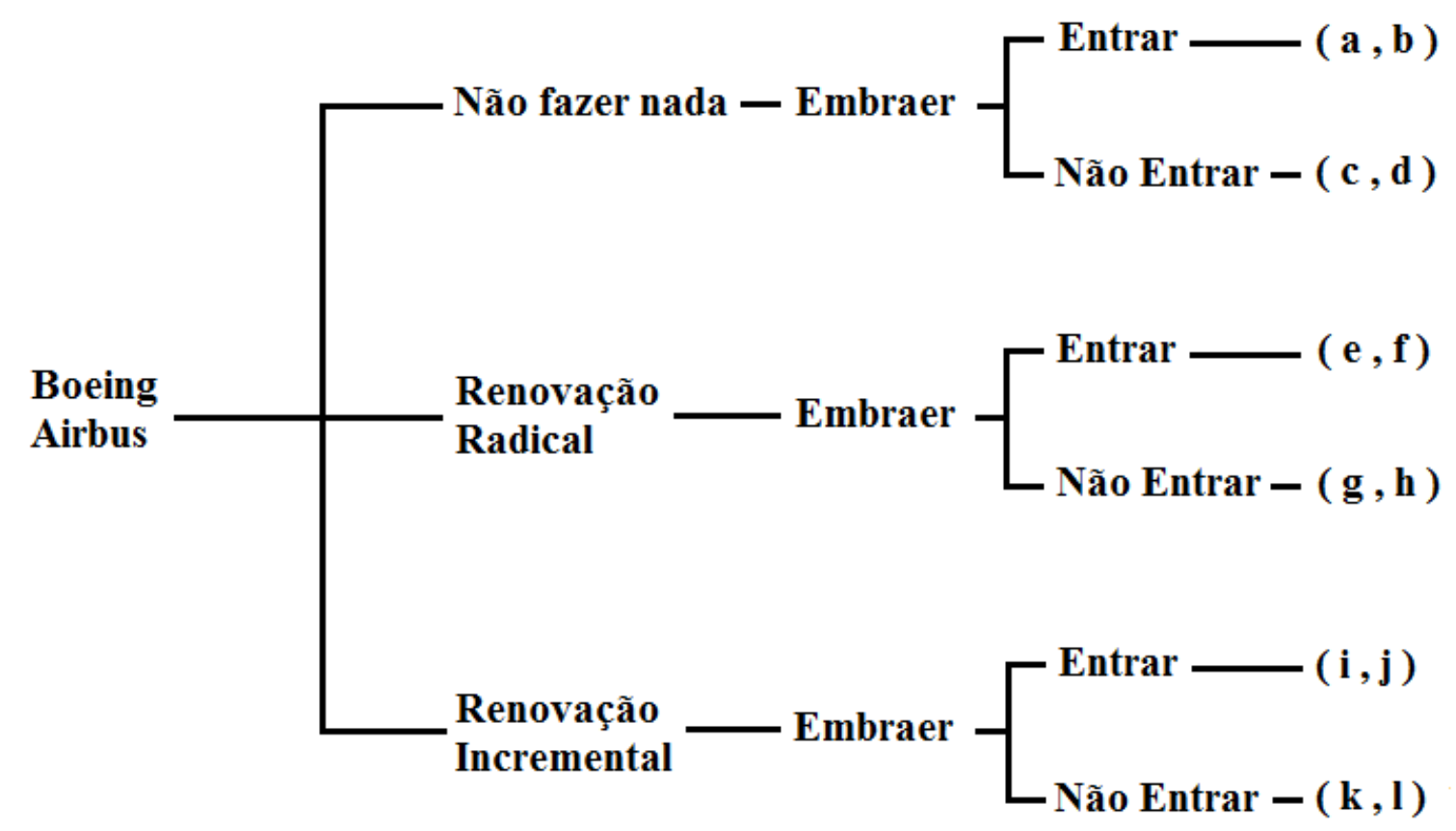

Figura 4 - Jogo sequencial para Embraer a partir da ação das lideres globais Boeing e Airbus $^{11}$

Em termos teóricos, todos os resultados expressos na Figura 4 são possíveis. No entanto, quais são as condições que devem prevalecer para que cada resultado se mostre um equilíbrio?

${ }^{11}$ Elaboração própria. 
Tabela 5 - Jogo sequencial para Embraer a partir da ação das lideres globais Boeing e Airbus $^{12}$

\begin{tabular}{lll}
\hline Cenário & $\begin{array}{l}\text { Alternativa } \\
\text { da Embraer }\end{array}$ & Independe do líder? \\
\hline 1) $b>d$ & Entrar & Não \\
2) $f>h$ & Entrar & Não \\
3) $j>$ I & Entrar & Não \\
\hline
\end{tabular}

Restrição para que se constitua em solução:

1) $a>c, a>e, a>g, a>i, a>k$

2) $e>a, e>c, e>g, e>i, e>k$

3) $k>a, k>c, k>e, k>g, k>i$

\section{Condição para que "Entrar" seja uma estratégia dominante:}

Se $a>c$ e e>g e i>k

Como mostra a Figura 4, para Embraer seria vantajoso a sua entrada nesse segmento com capacidade superior a 120 passageiros caso as empresas líderes optassem por realizar uma inovação radical, pois dessa maneira a Embraer teria maior capacidade de competir com as empresas já consolidadas nesse mercado, já que, com o desenvolvimento de novos modelos por parte de ambas as empresas, abstraindo a experiência já adquirida da Boeing e Airbus, há a possibilidade de uma reorganização do mercado e com isso parte dele seria obtida pela Embraer, caso as empresas líderes não realizassem nenhum tipo de modificação nos seus modelos de aeronaves já existentes, a Embraer ao entrar nesse mercado com uma nova família de aeronaves obteria uma grande vantagem sobre as empresas já consolidadas nesse segmento adquirindo parte significativa do mercado de aeronaves com capacidade acima de 120 passageiros. No entanto, o mais vantajoso para as empresas líderes seria a realização de uma renovação incremental, pois não teriam gastos com a produção de um novo modelo de aeronave, apenas com a atualização do modelo já consolidado no mercado, assim, para Embraer a sua entrada seria viável se os seus custos com o desenvolvimento de uma nova família de aeronaves forem compatíveis com os seus ganhos futuros nesse novo segmento.

\footnotetext{
${ }^{12}$ Elaboração própria.
} 
Ao analisar o segmento de 60 a 120 passageiros, no qual a Embraer é a empresa líder, podemos acompanhar o processo de tomada de decisão por parte da Embraer e posteriormente as decisões das novas empresas em concorrer ou não nesse nicho.

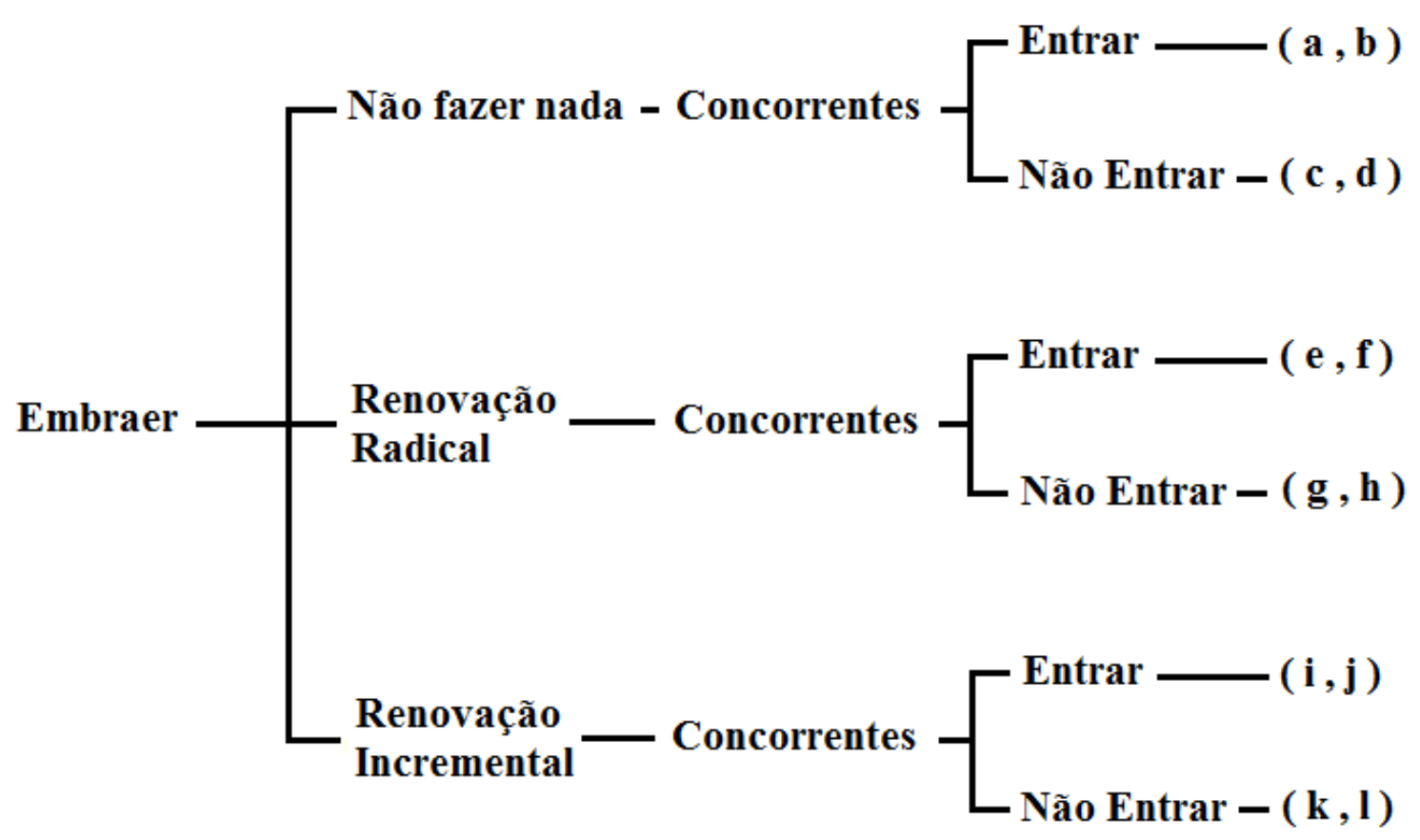

Figura 5 - Jogo sequencial para as concorrentes a partir da ação da líder regional Embraer $^{13}$

Ao analisar a Figura 5, percebemos que a escolha da Embraer é essencial para o aumento dos seus ganhos nesse segmento, ou seja, a tomada de decisão tem que levar em consideração as possíveis decisões das concorrentes.

${ }^{13}$ Elaboração própria. 


\section{Tabela 6 - Jogo sequencial para as concorrentes a partir da ação da líder regional}

\section{Embraer $^{14}$}

\begin{tabular}{lll}
\hline Cenário & $\begin{array}{l}\text { Alternativa das } \\
\text { Concorrentes }\end{array}$ & \multicolumn{1}{c}{ Independe do líder? } \\
\hline \begin{tabular}{lll} 
1) $b<d$ & Entrar & Não \\
2) $f>h$ & Entrar & Não \\
3) $\mathrm{j}>\mathrm{l}$ & Entrar & \multicolumn{1}{c}{ Não } \\
\hline Restrição de liderança: & 1) $a>c, a>e, a>g, a>i, a>k$ \\
& 2) $e>a, e>c, e>g, e>i, e>k$ \\
& 3) $i>a, i>c, i>e, i>g, i>k$
\end{tabular} \\
$\begin{array}{ll}\begin{array}{l}\text { Condição para que "Entrar" } \\
\text { seja uma estratégia } \\
\text { dominante: }\end{array} & \text { Se } a>c \text { e e }>g \text { e } i>k\end{array}$ \\
\hline
\end{tabular}

Nesse caso, como as concorrentes são empresas que possuem ajuda dos seus respectivos Estados e que tem o objetivo de competir mais diretamente nos respectivos mercados internos em larga expansão, é plausível supor que a entrada dessas novas empresas é quase certa, porém, o seus ganhos dependerão e muito das decisões da empresa líder. Logo, para a Embraer optar pela renovação incremental - a manutenção da família dos E-Jets realizando apenas algumas modificações a fim de melhorar o desempenho das aeronaves e se adaptar às exigências do mercado - seria a solução mais adequada, pois mesmo com a entrada de novas concorrentes ela ainda permaneceria como empresa líder.

A utilização de árvores de jogos sequenciais possibilita a análise de diferentes cenários nos quais algumas empresas precisam esperar a tomada de decisão das líderes de mercado para que a partir dessa escolha diferentes estratégias sejam tomadas, sempre buscando os maiores ganhos levando em consideração os riscos envolvidos.

\footnotetext{
${ }^{14}$ Elaboração própria.
} 


\section{Contraste das análises com as movimentações estratégicas efetivas}

Zwerdling (2012) narra que a ordem dos acontecimentos seguiu as seguintes etapas: Airbus anuncia em Dezembro de 2010 o lançamento da variante NEO (New Engine Option) para a família do A320, exceto para o menor dos membros da linha, o A318. Em Agosto de 2011, a Boeing anuncia o lançamento da variante Max para a família do B737. Assim como a decisão da Airbus, esta renovação da linha exclui o menor dos membros da família, o modelo B737600. Finalmente, em Novembro de 2011, a Embraer decidiu esperar pela decisão das empresas líderes, no caso, a Boeing e a Airbus, para tomar a decisão em relação a sua possível entrada no nicho de aeronaves com capacidade acima de 120 passageiros.

No segmento de aeronaves de grande porte, as empresas líderes são a Boeing e a Airbus, assim a Embraer teve que esperar a tomada de decisões dessas grandes empresas para posteriormente fazer a sua escolha de renovação radical, renovação incremental, subir para o segmento de aeronaves com capacidade acima de 120 passageiros ou não tomar nenhuma decisão. Assim o que realmente aconteceu foi uma relativa demora na tomada de decisão das líderes, sendo que, ambas tomaram as suas decisões praticamente simultaneamente. A Figura 6 é que melhor demonstra as possíveis escolhas dessas empresas tendo como base a conjuntura do mercado. 


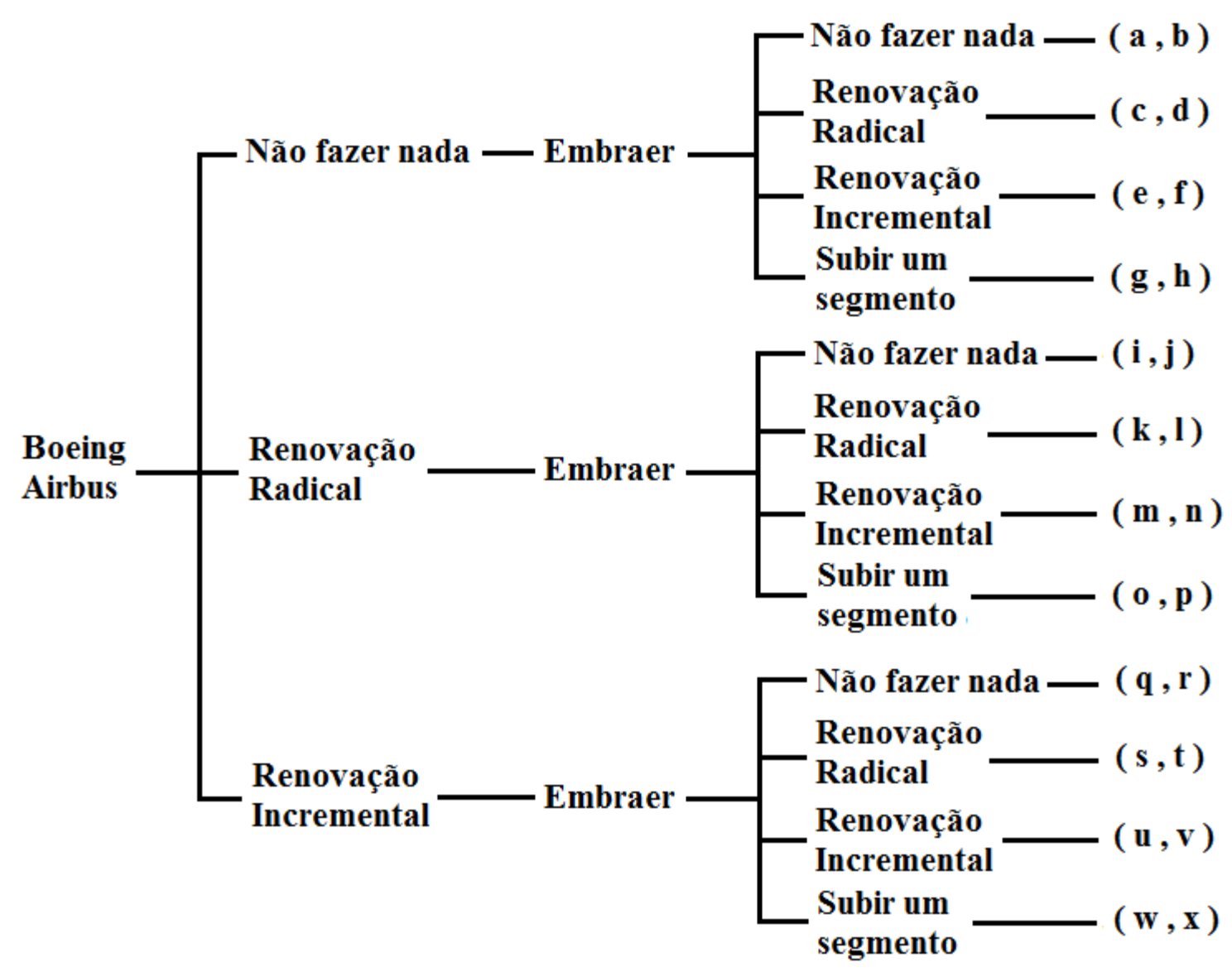

Figura 6 - Jogo sequencial completo para Embraer a partir da ação das líderes globais Boeing e Airbus ${ }^{15}$

${ }^{15}$ Elaboração própria. 
Tabela 7 - Jogo sequencial completo para a Embraer a partir da ação das líderes globais Boeing e Airbus ${ }^{16}$

\begin{tabular}{lll}
\hline Cenário & $\begin{array}{l}\text { Alternativa da } \\
\text { Embraer }\end{array}$ & Independe do líder? \\
\hline 1) $h>f>d>b$ & Subir de segmento & Não \\
2) $I>n>p>j$ & Inovação radical & Não \\
3) $v>x>t>r$ & Inovação incremental & Não \\
\hline
\end{tabular}

Restrição de liderança:

1) $g>a, g>c, g>e, g>i, g>k, g>m, g>0, g>q, g>s$, g>u, $g>w$

2) $k>a, k>c, k>e, k>g, k>i, k>m, k>0, k>q, k>s$, $\mathrm{k}>\mathrm{u}, \mathrm{k}>\mathrm{w}$

3) $u>a, u>c, u>e, u>g, u>i, u>k, u>m, u>0, u>q$, $\mathrm{u}>\mathrm{s}, \mathrm{u}>\mathrm{w}$

A análise da Figura 6 permite afirmar que, dado os possíveis ganhos da Boeing e Airbus referente às opções de renovação radical, incremental ou não fazer uma renovação, a estratégia dominante das empresas líderes seria optar pela renovação incremental, já que neste caso o seu ganho seria no mínimo próximo aos eventuais ganhos obtidos caso a renovação radical fosse implementada. E como de fato aconteceu, as empresas líderes a princípio demoraram um pouco para tomarem as suas decisões, mas quando ocorreu foi praticamente de forma simultânea: a Airbus foi a primeira a divulgar que iria manter a família A320 e realizar apenas algumas modificações nos modelos para adequar as exigências do mercado, praticamente na sequência, a Boeing também revelou a sua manutenção da família de aeronaves 737 e assim como a Airbus, faria apenas algumas mudanças nos seus modelos. Portanto, a partir do posicionamento das líderes a Embraer pode analisar as suas escolhas de renovação, e como ilustrado na Figura 6, a melhor estratégia para a Embraer seria a renovação incremental, pois proporcionaria a Embraer um ganho maior dado à escolha das empresas líderes. Isso foi constatado com a divulgação da Embraer na manutenção dos E-Jets e a posterior mudança dos motores dessa família de aeronaves para motores com maior autonomia e com menor produção de ruídos.

\footnotetext{
${ }^{16}$ Elaboração própria.
} 


\section{Conclusão}

O presente trabalho foi um ensaio no sentido de sugerir a utilização da Teoria dos Jogos na solução de dilemas envolvendo a tomada de decisão no mercado de fabricação de aeronaves. A escolha do empasse tecnológico envolvendo a empresa brasileira Embraer no ano de 2011 exigiu a contextualização do complexo cenário para este setor que começou a se desenhar em meados dos anos 2000 e promete intensificar a concorrência internacional ao longo das próximas décadas.

A entrada de novos players e a gama de opções tecnológicas que o avanço cientifico proporciona podem parecer impeditivos para a simplificação do cenário por meio de um modelo em Teoria dos Jogos, já que amplia consideravelmente as variáveis relevantes. No entanto, foi possível evidenciar alguns sinais dados pelo mercado de antemão que excluem alguns caminhos improváveis, seja por inviabilidade financeira ou por conta de barreiras de mercado. Um exemplo é o fato de as tomadas de decisão das menores empresas serem geralmente tomadas depois que as empresas líderes já terem sinalizado algum caminho. Desta forma, o modelo baseado em Teoria dos Jogos pode colaborar com a simulação dos cenários mais prováveis e as combinações de resultados possíveis associados a cada tomada de decisão.

Ainda ficam algumas questões em aberto, sendo a principal delas em relação ao valor de payoff esperado a ser usado como ferramenta para o modelo. Uma forma de se dar outro grau de robustez ao modelo seria por meio da obtenção de estimativas para os fluxos de caixa descontados que, de fato, devem compor os payoffs das matrizes e das árvores de decisão. Esses payoffs devem advir de todo o exame do ganho esperado com a introdução de um programa e, forçosamente, incluir as empresas aéreas, clientes que são dos programas desenvolvidos pelos fabricantes de aeronaves. 


\section{Referências}

Altfeld, H-H. (2010) Commercial Aircraft Projects: managing the development of highly complex products. Surrey: Ashgate Publishing Company.

Bernardes, R. (2000) Embraer: elos entre Estado e Mercado. São Paulo, SP: Hucitec / FAPESP

Bettini, H. F. A. J. (2007) A Fabricação de Aeronaves além da Engenharia Aeronáutica. Mimeo.

Bettini, H. F. A. J. e Oliveira, A. V. M. (2011) Transporte aéreo regional: entre economias de densidade e custos de transação. Journal of Transport Literature, vol. 5, n. 4, pp. 171-187.

Brito, J. N. P. e Bragança, J. C. O. (2008) Competitive dynamics and technological strategies in the regional aircraft industry: an evolutionary perspective. Proceedings for the $12^{\text {th }}$ International Schumpeter Society Conference.

Commercial Aircraft Corporation of China - Comac (2011) Disponível em english.comac.cc

Empresa Brasileira de Aeronáutica S.A. (2000) Embraer relatório anual.

Empresa Brasileira de Aeronáutica S.A. (2001) Embraer relatório anual.

Empresa Brasileira de Aeronáutica S.A. (2002) Embraer relatório anual.

Empresa Brasileira de Aeronáutica S.A. (2003) Embraer relatório anual.

Empresa Brasileira de Aeronáutica S.A. (2004) Embraer relatório anual.

Empresa Brasileira de Aeronáutica S.A. (2005) Embraer relatório anual.

Empresa Brasileira de Aeronáutica S.A. (2006) Embraer relatório anual.

Empresa Brasileira de Aeronáutica S.A. (2007) Embraer relatório anual.

Empresa Brasileira de Aeronáutica S.A. (2008) Embraer relatório anual.

Empresa Brasileira de Aeronáutica S.A. (2009) Embraer relatório anual.

Empresa Brasileira de Aeronáutica S.A. (2010) Embraer relatório anual.

Empresa Brasileira de Aeronáutica S.A. (2011) Embraer market outlook.

Exame (2011a) Boeing e Airbus declaram fim do duopólio. Disponível em exame.abril.com.br

Exame (2011b) Embraer estuda novas famílias de aeronaves. Disponível em exame.abril.com.br

Exame (2011c) Embraer encara futuro desafiador na aviação comercial. Disponível em exame.abril.com.br

Ferreira, M. J. B. (2009) Dinâmica da inovação e mudanças estruturais: um estudo de caso da indústria aeronáutica mundial e a inserção brasileira. Tese (doutorado) Campinas: UNICAMP.

Fiani, R. (2006). Teoria dos jogos com aplicações em economia, administração e ciências sociais. Rio de Janeiro: Elsevier / Campus.

Financial Times (2011) Boeing and Airbus call time on duopoly. Disponível em www.ft.com

Flightglobal (2011) Disponivel em www.flightglobal.com

Gulliver (2011) The Russians are coming - and the Chinese and the Canadians. Disponível em www.economist.com

Mitsubishi Aircraft Corporation (2011) MRJ Catalogue. Disponível em www.mrj-japan.com

Norris, G. e Wagner. M. (1999) Airbus. Osceola, WI: MBI Publishing 
Portal Estadão (2011) Mitsubishi começa a fabricar avião que concorrerá com a Embraer. São Paulo. O Estado de São Paulo. Disponível em www.estadao.com.br.

Sobrinho, A. A., Marins, F. A. S. e Batista Júnior, E. D. (2005) Decisão de investimento em projetos de pesquisa e desenvolvimento usando a teoria das opções reais. XXV Encontro Nacional de Engenharia de Produção, Porto Alegre: UFRGS, 2005, pp 2195-2202.

Sobrinho, A. A., Marins, F. A. S. e Batista Júnior, E. D. (2006) Opções de avaliação estocástica: Otimizando a decisão de carteiras de investimentos. XXXVIII Simpósio Brasileiro de Pesquisa Operacional, Goiânia: UFG, 2006, pp. 662-669.

Sukhoi Civil Aircraft (2011) SSJ100: Product Brochure. Disponível em www.sukhoi.org

The Boeing Company (2009) Annual report.

The Boeing Company (2010) Annual report.

Zwerdling, R. (2012) Disputa acirrada: Max vs. Neo. Revista Flap Internacional, ed. 473. São Paulo: Grupo Editorial Spagat. 